Canadian Journal of Fisheries and Aquatic Sciences

Canadian

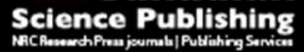

Journal canadien des sciences halieutiques et aquatiques

\title{
Forecasting the response of Great Lakes sea lamprey (Petromyzon marinus) to barrier removals
}

\begin{tabular}{|r|l|}
\hline Journal: & Canadian Journal of Fisheries and Aquatic Sciences \\
\hline Manuscript ID & cjfas-2017-0243.R1 \\
\hline Manuscript Type: & Article \\
\hline Date Submitted by the Author: & $01-$ Nov-2017 \\
\hline $\begin{array}{r}\text { Complete List of Authors: } \\
\text { Is the invited manuscript for } \\
\text { consideration in a Special } \\
\text { Issue? : }\end{array}$ & $\begin{array}{l}\text { Jensen, Alexander; Michigan State University, Fisheries and Wildlife } \\
\text { Jones, Michael; Michigan State University }\end{array}$ \\
\hline Keyword: & $\begin{array}{l}\text { dam removal, management strategy evaluation, sea lamprey, HABITAT < } \\
\text { General, Great Lakes }\end{array}$ \\
\hline
\end{tabular}


Title:

2 Forecasting the response of Great Lakes sea lamprey (Petromyzon marinus) to barrier removals 3

Authors:

Alexander James Jensen ${ }^{1}$

jensen.alex1502@gmail.com

Michael L. Jones ${ }^{1}$

jonesm30@msu.edu

9

\section{Author Affiliation/Address:}

$11{ }^{1}$ Michigan State University, Department of Fisheries and Wildlife, 13 Natural Resources Bldg,

\section{Corresponding Author:}

Alexander J. Jensen

16 Michigan State University, Department of Fisheries and Wildlife, 13 Natural Resources Bldg,

$$
\text { (207) 659-2226 (Phone) }
$$

$$
\text { (517) 432-1699 (Fax) }
$$




\section{Abstract}

22 A key uncertainty surrounding barrier removals in the Great Lakes is the response of

23 invasive sea lamprey populations to realized increases in available habitat for adfluvial species.

24 We addressed this uncertainty by applying a management strategy evaluation model, originally

25 developed to inform sea lamprey management in the Great Lakes, to forecast the effects of

26 barrier removal on Lake Michigan sea lamprey abundances. We used this model to characterize

27 the response to systematically increasing habitat availability and a specific proposed barrier

28 removal. Our results suggest the removals allow novel production from newly opened habitat

29 and, assuming a fixed budget for sea lamprey control, decrease the overall effectiveness of

30 control, leading to disproportionate increases in abundance. The case study demonstrated that

31 evaluating population effects only at the scale of watersheds directly affected by barrier removals

32 would substantially underestimate effects at the scale of Lake Michigan. Similar population

33 responses are possible when evaluating the effects on desired species. Our findings highlight the

34 importance of considering trade-offs for barrier removals and selecting the appropriate scale for

35 forecasting. 


\section{Introduction}

Dams are ubiquitous features of watersheds throughout the world, and historically provided many societal benefits, but they also serve as significant barriers to migratory fish. Indeed, dams, hereafter referred to as stream barriers or simply barriers, have been implicated in the declines of numerous populations of diadromous species (Limburg and Waldman 2009).

Thanks to growing public preference to increase lotic connectivity and benefit aquatic species, barrier removal in the U.S. is accelerating and many large-scale structures have been demolished in systems like the Penobscot, Carmel, and Elwha Rivers in Maine, California, and Washington, respectively. Observed ecological benefits from previous barrier removals include increased biological diversity, restoration of historical habitat, and enhanced passage (Bednarek 2001). Ecological trade-offs emerge, however, when improved river access eliminates impediments to the spread of unwanted species (McLaughlin et al. 2013). By restricting the range expansion of invasive species, stream barriers in select systems may actually provide an important conservation function by blocking fish migration (Sharov and Liebhold 1998; Vélez-Espino et al. 2011; Rahel 2013).

Sea lamprey have caused considerable ecological and economic damage within the Laurentian Great Lakes since their invasion in the early $20^{\text {th }}$ century (Smith and Tibbles 1980). The parasitic juvenile stage of this species feeds on Great Lakes fish before maturing and migrating to Great Lakes tributaries to spawn; the resulting larvae live as burrowing filterfeeders in these streams for several years before metamorphosing and migrating back to the lakes to begin their parasitic stage (Applegate 1950). Sea lamprey are currently controlled to generally acceptable population levels in the Great Lakes using a combination of lamprey-specific pesticide (i.e., lampricide) applications and intentional fragmentation (Smith and Tibbles 1980). 
59 A limited budget is allocated annually to both elements of control. Stream barriers play an

60 important role by preventing migratory adult sea lamprey from accessing high quality spawning

61 habitat, and consequently eliminating the need for costly treatments of large sections of rivers

62 (Hunn and Youngs 1980). The Great Lakes Fishery Commission (GLFC) Sea Lamprey Control

63 Program (SLCP) uses both pre-existing and actively constructed stream barriers to block sea

64 lamprey migration (Lavis et al. 2003).

In concert with the prospective benefits to resident fish species including various

66 salmonids and lake sturgeon (Acipenser fulvescens), Great Lakes barrier removals have the

67 potential to greatly reduce the effectiveness of sea lamprey control. In the Lake Michigan basin

68 alone, barriers like the Sixth Street Dam, Union Street Dam, and Calkins Bridge Dam currently

69 block hundreds of miles of viable spawning and larval habitat in the Grand River, Boardman

70 River, and Kalamazoo River, respectively. If these structures were removed without

71 construction of a replacement lamprey barrier or an increase in the lampricide control budget,

72 there would be two options available to control agents: 1) ignore production from the newly

73 available habitat, or 2) re-allocate lampricide application efforts to the newly available habitat as

74 needed, at the expense of reducing the frequency of applications in other river systems. The first

75 option is unlikely to be considered for large systems like the Grand River, while the second

76 option requires a shift in control effort from existing stream systems to the new habitat,

77 potentially decreasing treatment effectiveness across the basin as a whole. Although the

78 qualitative risks of barrier removal for sea lamprey management in the Great Lakes are accepted

79 by fishery management agencies, there is a need to better understand the actual magnitude of the

80 sea lamprey response to barrier removals. 
In addition to the ecological concerns surrounding barrier removals, decision-makers are

82 faced with numerous competing objectives and pressures, including the maintenance of

83 infrastructure condition and public safety, generation of power, and enhancement of recreational

84 opportunities. The development of formal criteria, supported by the necessary scientific and

85 social information, is one solution for managing these trade-offs (Pejchar and Warner 2001).

86 With respect to the scientific information, researchers are specifically arguing for more careful,

87 comprehensive consideration of the potential ecological consequences and an increased role for

88 scientists in providing data on these consequences (Johnson and Graber 2002; Doyle et al. 2003).

89 In the case of barrier removals in the Great Lakes, research that equips managers with a more

90 explicit understanding of the effects of barrier removals on sea lamprey control can help

91 formalize the balancing of trade-offs inherent in decision-making.

92 Evaluating the expected effects of barrier removals requires consideration for the

93 appropriate spatial scale of modeling and relevant aspects of habitat quality upstream of barriers.

94 Most previous studies have focused on river-specific impacts of barrier removals (Stanley et al.

95 2007; Burroughs et al. 2010). The effects of barrier removals on sea lamprey populations,

96 however, are not restricted to river-specific production, as sea lamprey appear to exhibit a lack of

97 natal homing when migrating to tributaries to spawn (Bergstedt and Seelye 1995). Sea lamprey

98 production from a specific river can influence future spawner abundances in other rivers, so

99 predicting the effects of barrier removals on Great Lakes requires a consideration of population

100 dynamics on a larger scale than that of individual rivers. Furthermore, both the quality and

101 quantity of habitat upstream of barriers needs to be evaluated. Sea lamprey recruitment is known

102 to be limited by the availability of larval habitat, defined as substrate dominated by fine

103 sediments (Slade et al. 2003), and the attractiveness of river systems to migrating spawners is 
104 partially driven by habitat quality and quantity (Morman et al. 1980; Mullett et al. 2003).

105 Previous modeling efforts looking at the effect of changing habitat availability on other fish

106 species have also emphasized the importance of habitat quality in predicting population

107 responses (Cheng et al. 2006; van der Lee and Koops 2016).

108 Management strategy evaluation (MSE) modeling, using known information about sea

109 lamprey life history and control in the Great Lakes, represents a feasible, realistic means to

110 capture the expected effects of barrier removals on the long-term effectiveness of sea lamprey

111 control. Management strategy evaluation models are powerful tools for research and

112 management because they tie together biological, observational, and management processes,

113 account for sources of uncertainty in each of these processes, and allow researchers to formally

114 compare the ability of competing management strategies to achieve specified management

115 objectives (Smith et al. 1999; Harwood and Stokes 2003). We have already developed an MSE

116 model for sea lamprey, specific to the Great Lakes, to assess the effect of alternative

117 management strategies (Jones et al. 2009). This model has been used to determine optimal

118 control budgets to achieve target economic injury levels (Irwin et al. 2012) and to explicitly

119 compare the effectiveness of alternative management strategies at a basin-wide scale (Dawson et 120 al. 2016).

121 We modified the MSE model to evaluate the effects of barrier removals on the Lake

122 Michigan sea lamprey population. Lake Michigan was selected as the focal spatial scale for this

123 work due to the observed lack of natal homing for sea lamprey within lakes and the detailed

124 understanding of sea lamprey population dynamics in this region (Dawson et al. 2016). We first

125 assessed the system's general response to increasing habitat availability through the incremental

126 addition of discrete habitat units with varying attributes of habitat quality. We also modeled a 
127 specific Lake Michigan barrier removal scenario, using input data and management scenarios

128 defined by sea lamprey control agents, to inform decision-making for a contentious,

129 contemporary barrier removal scenario. Both approaches helped explain how a complex,

130 intensively managed biological system would respond to anthropogenic changes in habitat

131 availability. 


\section{Methods}

\section{Model Description}

134 To evaluate the potential effect of barrier removals on sea lamprey production within an

135 MSE framework, we modified the MSE operating model developed by Jones et al. (2009) and

136 updated by Dawson et al. (2016). Briefly, this operating model includes interconnecting

137 biological, observational, and management components, operates at the spatial scale of an entire

138 Great Lake, and has an annual time step (Fig. 1). The biological model simulates the life history

139 of sea lamprey: adult sea lamprey from the lake habitat are allocated to streams for spawning;

140 these spawners produce stream-dwelling larvae according to a Ricker-type stock-recruitment

141 function; the larvae experience growth and mortality before metamorphosing into the parasitic

142 juvenile stages and migrating back to the lake. An observational model generates estimates of

143 stream-specific larval abundances intended to reflect measurement uncertainty with existing

144 sampling methods in the Great Lakes; these estimates are used to rank stream segments, called

145 treatment units, for treatment on the basis of cost per expected larva killed in the entire segment.

146 Treatment units are operationally defined as river sections treated with lampricides as a single

147 unit. The number of annually selected treatment units is limited by the total available control

148 budget. Treatment units selected for lampricide applications experience reductions in larval

149 abundance; the actual proportional reduction in abundance due to a lampricide treatment is

150 drawn from a beta distribution yielding average reductions of $93 \%$ and a CV of 0.10 . Process

151 uncertainty is also included in the model in the form of a stochastic reproduction function

152 (Dawson and Jones 2009) and uncertainty in stream-specific larval growth rates. Further details

153 of the model's structure and parameterization are not repeated here; interested readers are

154 referred to earlier papers. 
In addition to incorporating the capacity to flexibly add new habitat, as described below,

156 the model was altered to account for recent analyses of adult sea lamprey trapping data that re-

157 assessed the rules for allocating adult sea lamprey to spawning habitats. These modifications

158 included the following: 1) allocating 52\% and $48 \%$ of all Lake Michigan spawners to northern

159 and southern tributaries, respectively, prior to allocating spawners to individual streams based on

160 drainage area and larval abundance, and 2) increasing the influence of drainage area, relative to

161 larval abundance, in determining spawner allocation to individual tributaries. Tributaries were

162 classified as northern or southern based on the location of their mouths relative to a dividing line

163 stretching across Lake Michigan from Frankfort, MI, to just south of Manistique, MI (Mullett et

164 al. 2003). These changes were made to match simulated spawner numbers with observed adult

165 distributions in sixteen Lake Michigan rivers that have received previous spawner assessments

166 (H. Dawson and M.L. Jones, Quantitative Fisheries Center, Michigan State University, East

167 Lansing, Michigan, unpublished analysis), and to reflect an updated analysis of sea lamprey

168 trapping data from throughout the Great Lakes that examined covariates affecting relative

169 spawning run size (Mullett et al. 2003; M.L. Jones, Quantitative Fisheries Center, Michigan State

170 University, East Lansing, Michigan, unpublished data).

171 Population Responses to Systematic Barrier Removals

172 We first characterized the general response of the Lake Michigan sea lamprey population

173 to barrier removals by systematically adding standardized habitat blocks. Each block was

174 assigned identical attributes, including areas of suitable larval sea lamprey habitat types as

175 defined by the GLFC (i.e., Type I and Type II; Slade et al. 2003), drainage area, treatment cost,

176 and miscellaneous larval growth and mortality parameters; these are all attributes of existing

177 treatment units within the original operating model. Block attributes were calculated as averages 
178 of all existing treatment units in Lake Michigan; each habitat block was assigned a total larval

179 habitat area of $386,275 \mathrm{~m}^{2}$, drainage area of $842.8 \mathrm{~km}^{2}$, and treatment cost of $\$ 127,864$. These

180 habitat additions were intended to simulate the effect of opening new river systems to sea

181 lamprey (i.e., removing barriers at the river mouths).

182 The systematic addition of habitat was conducted in two ways: 1) combine new habitat

183 blocks into an ever larger single treatment unit or 2) add habitat blocks as multiple, discrete

184 treatment units. These two approaches were intended to contrast the effect of opening a single

185 large river with the effect of opening numerous small tributaries, with the same overall increase

186 in total habitat area. The single river is considered for treatment as a stand-alone system,

187 whereas each of the added small tributaries was ranked separately. When additional habitat

188 blocks were combined to form the single treatment unit, the total habitat area, drainage area, and

189 treatment cost were correspondingly increased in a 1:1 relationship; a treatment unit composed

190 of six habitat blocks would therefore have twice the drainage area, treatment cost, and habitat

191 area as one composed of three such blocks. We systematically assessed the effect of increased

192 habitat availability by adding three habitat blocks at a time. This was a convenient scale of

193 analysis because nine additional habitat units represent a $10 \%$ increase in total habitat

194 availability across Lake Michigan. In the end, we chose to evaluate increasing habitat

195 availability up to an additional 18 habitat units, representing a plausible range of changes in

196 overall habitat given existing barrier removal proposals in the Lake Michigan basin.

197 The influence of two categorical treatment unit attributes, namely recruitment potential

198 and geographically-determined spawner allocation, on the sea lamprey response to barrier

199 removals were formally evaluated by running increasing habitat addition simulations for each

200 possible combination of attributes. New habitat areas were either characterized as having high or 
201 low recruitment potential, reflecting observed (Dawson et al. 2016) differences in Ricker stock-

202 recruitment parameter estimates between streams classified by sea lamprey program control staff

203 as regular versus irregular producers. Dawson et al. (2016) reported that recruitment potential

204 (Ricker $\alpha$ estimates) was 3.4x greater in regular producers. Furthermore, habitat units were 205 characterized as having elevated or reduced spawner allocation, based on whether they were 206 assigned to northern or southern Lake Michigan, respectively. New habitat regions added to 207 northern Lake Michigan were regarded as having elevated spawner allocations because $52 \%$ of 208 all Lake Michigan spawners are assigned to this region, despite containing smaller rivers with 209 smaller drainage areas and corresponding attractive flows for migrating sea lamprey compared to 210 southern Lake Michigan.

211 For each removal scenario, we ran the model for 5000 simulations, with a 100 year time

212 horizon for each simulation; this was intended to capture the full range of stochasticity in model

213 results and yield an equilibrium state for each simulation. For every simulation, the mean

214 number of total lake-wide adult spawners across the last ten years was calculated to represent

215 expected equilibrium conditions. The mean system response for each habitat addition scenario

216 was summarized by calculating the percent change in mean abundance, across simulations, from

217 status quo mean abundance using the equation below, in which the original value refers to mean

218 status quo abundance unless otherwise stated:

$$
\frac{(\text { New Value - Original Value })}{\text { Original Value }} \times 100
$$

The simulated range of variation for each scenario represented variability among the

221 simulation-specific 10-year averages. We also took advantage of the stochastic nature of the 222 simulations to calculate the proportion of the 5000 simulations, for each habitat addition 223 scenario, exceeding a high threshold relative to average status quo spawner abundance; we 
224 selected an abundance of 152266 spawners based on the $90^{\text {th }}$ percentile of simulated lamprey

225 abundances under status quo conditions. This simulated threshold abundance is similar to the

226 maximum estimated Lake Michigan adult abundance of 141730 over a recent 10-year period

227 (2005-2014). Finally, to calibrate the model at the current Lake Michigan control budget of

228 \$2.42 million, larval survival was adjusted until the base model (i.e., no habitat additions)

229 successfully projected the recently estimated average adult abundance of 72200 (M. Siefkes,

230 Great Lakes Fishery Commission, Ann Arbor, Michigan, personal communication, 2016).

231 Explaining Forecasted Population Trends

232 To explain the forecasted trends in adult sea lamprey abundance with increasing habitat

233 availability, we ran additional simulations to characterize trends in the following model

234 components: stream-specific parasitic sea lamprey production, control budget allocation among

235 the newly added and original treatment units, and lampricide treatment frequency. Parasitic sea

236 lamprey production reflected the total number of metamorphosed sea lamprey leaving streams in

237 each year and simulation. Tracking stream-specific production facilitated comparison of the

238 relative contribution of the new and original treatment units to lake-wide adult abundances.

239 Additionally, looking at both control budget allocation and treatment frequency helped to explain

240 why the relative contributions of sea lamprey production from new and original treatment units

241 might change with increasing habitat availability.

242 We ran these additional simulations 1000 times over the same 100 year timespan;

243 consistent with other simulations, only the last ten years of data in each simulation were used to

244 characterize trends. Simulations were run only for increasing habitat availability in which

245 regular producing streams were added to northern Lake Michigan, as these attributes produced

246 the strongest trends in sea lamprey abundance and were therefore more amenable for elucidating 
247 population drivers. These simulations were run for the full range of increasing habitat

248 availability and for both the single large and multiple small river additions. We expect

249 qualitative patterns to be similar for other scenarios, such as simulating increasing habitat

250 availability in southern Lake Michigan streams.

251 Case Study: Simulating A Barrier Removal on Michigan's Grand River

252 We selected the potential removal of Michigan's Sixth Street Dam to demonstrate the

253 utility of an MSE approach in informing a potentially high impact barrier removal scenario. The

254 Sixth Street Dam is located in downtown Grand Rapids, MI, and has served as an important

255 incidental lamprey barrier on the Grand River, Michigan's longest river system. Approximately

25696 river km lies between the Sixth Street Dam and the Webber Dam, the next upstream barrier

257 on the mainstem, and numerous large tributaries, including the Thornapple, Maple, and Rogue

258 Rivers drain into the Grand River between the two barriers, in addition to many smaller streams

259 (Fig. 2).

260 Recently, there has been pressure by citizen stakeholders to remove this barrier, with the

261 primary goals of recreating the historical rapids and establishing new recreational boating

262 opportunities (Adair and Sullivan 2015). Thanks in large part to the current relevance and

263 extent of currently protected upstream habitat, the Sixth Street Dam removal scenario was listed

264 a high priority for modeling by SLCP managers (P. Hrodey and M. Siefkes, Great Lakes Fishery

265 Commission, Ann Arbor, Michigan, personal communication, 2015). Furthermore, this system

266 can also be modeled with some degree of accuracy given the quantity of compiled data; SLCP

267 surveys for larval habitat quantities and native lamprey densities were conducted in 2014 and

2682015 , in addition to the recent development of treatment cost estimates for the area. 
To simulate the removal of the Sixth Street Dam, we incorporated sixteen new treatment

270 units between the Sixth Street Dam and Webber Dam, each representing distinct Grand River

271 tributaries, into the model database. The mainstem of the Grand River was deemed likely to host

272 relatively low densities of larvae, thereby making treatment prohibitive from a cost-effective

273 standpoint (Fig. 2; J. Tews, U.S. Fish and Wildlife Service, Ludington, MI, personal

274 communication, 2015). Each included treatment unit was known to contain viable habitat for

275 spawning and larval sea lamprey, and had a uniquely estimable treatment cost. Additional

276 attributes of the new treatment units were then estimated using all available data on the Grand

277 River (supplementary data are available online).

278 Three primary management decisions were selected as the focus for modeling work: the

279 decision to modify the Webber Dam to block sea lamprey, the decision to treat or ignore the

280 newly available habitat upstream of the Sixth Street Dam, and the decision to maintain or

281 increase the current lake-wide control budget (Table 1). Because the Webber Dam currently has

282 the potential to pass sea lamprey but can be modified to block them, we simulated the influence

283 of barrier modification by allowing or denying sea lamprey access to the Looking Glass River;

284 this river is the only major tributary between the Webber Dam and the next mainstem barrier.

285 The decision to treat or ignore habitat upstream of the Sixth Street Dam was intended to compare

286 the effect of pulling treatment effort away from other Lake Michigan tributaries with the effect

287 of allowing uninhibited lamprey production above the Sixth Street Dam, respectively. Finally,

288 for the scenario in which the upstream system is treated and the Webber Dam blocks access to

289 the Looking Glass River, we both evaluated the effect of treating the system under the current

290 budget of $\$ 2.42$ million and estimated the necessary budget increase to prevent a lake-wide

291 increase in sea lamprey abundance above status quo levels. 
We also formally assessed the influence of the assumed degree to which sea lamprey

293 utilize the newly available larval habitat upstream of the Sixth Street Dam. Among all inputs,

294 larval habitat quantity is especially important to evaluate given its observed role in influencing

295 recruitment success (Jones et al. 2003) and explicit incorporation into the operating model (Jones

296 et al. 2009). We therefore assessed the response of sea lamprey to two levels of assumed habitat

297 use within added tributaries for each of the control scenario combinations: $10 \%$ and $50 \%$ habitat

298 use. The 10\% habitat use represents a reasonable approximation of expected lamprey use of total

299 river length based on professional judgment (A. Jubar, U.S. Fish and Wildlife Service,

300 Ludington, Michigan, personal communication, 2016) and preliminary analyses indicating that

301 the lengths of existing Grand River treatment units (obtained from the SLCP's database)

302 averaged just $10 \%$ of the total tributary lengths calculated from the GIS-based Sea Lamprey

303 Control Map (Great Lakes Fishery Commission 2016; A. Jensen, Michigan State University,

304 East Lansing, Michigan, unpublished analysis). Expected use of total river length is as low as

$30510 \%$ because linear referencing, in which even marginal lotic habitats unsuitable for larval sea

306 lamprey (e.g., drainage ditches, ephemeral headwater creeks) are digitized to form stream GIS

307 datasets, can produce overestimates of total river lengths. We chose to assess the influence of

$30850 \%$ habitat use on the sea lamprey response in order to evaluate a presumed worst-case scenario

309 for extent of habitat use.

310 The model was run and summarized in the same manner as for the systematic habitat

311 additions (i.e., 5000 simulations, 100 year time horizon, ten year averages) for every scenario

312 and assumption, and the proportions of simulation results above the same status quo threshold

313 were again calculated. 


\section{Results}

\section{Population Responses to Systematic Barrier Removals}

316 The simulated Lake Michigan sea lamprey population exhibited a nonlinear increase in

317 abundance in response to systematically increasing habitat availability that varied in magnitude

318 across the combinations of habitat addition attributes (Figs. 3, 4). The smallest percent increase

319 in mean abundance from status quo conditions with a $20 \%$ increase in habitat availability was

$320161 \%$; the greatest increase exceeded $800 \%$. The type of barrier removal (i.e., whether there is

321 one large-scale barrier removal or multiple small-scale events) influenced the magnitude of the

322 sea lamprey population's response to barrier removal, with the addition of a single large stream

323 having the greater effect. The largest percent increase in abundance for the single stream

324 addition was $885 \%$, compared to $452 \%$ for multiple stream additions. This difference in

325 abundance between the types of habitat addition held true across all combinations of recruitment

326 potential and spawner allocation. Corresponding with the different trends in mean abundance,

327 the proportion of simulations with forecasted abundances greater than the high threshold relative

328 to status quo abundance (152 266) also approached one more rapidly, relative to the amount of

329 added habitat, when additions were conducted as a single large river.

330 Whether the additional accessible habitat had high or low recruitment potential, as well as

331 whether it experienced high or low spawner allocation, also had implications for the simulated

332 effectiveness of sea lamprey control under barrier removal scenarios. Habitat additions with

333 high recruitment potential and high spawner allocation, which would correspond to habitat

334 assigned the status of regular producers and added to northern Lake Michigan, resulted in higher

335 abundances than habitat additions with low recruitment potential and low spawner allocation

336 (Figs. 3, 4). Between these two categorical factors, recruitment potential had the slightly greater 
337 effect on resulting adult sea lamprey abundances. With a $20 \%$ increase in habitat availability and

338 the combination of spawner allocation and type of habitat addition held constant, high

339 recruitment habitat additions resulted in $38.2 \%$ to $115 \%$ greater mean adult sea lamprey

340 abundances relative to abundances arising from habitat additions with low recruitment potential.

341 With the same 20\% increase in habitat availability, high spawner allocation habitat resulted in

342 mean abundances $23.3 \%$ to $92.2 \%$ greater than those achieved under habitat additions with low

343 spawner allocation.

344 Explaining Forecasted Population Trends

345 A combination of novel sea lamprey production from newly added habitat and increasing

346 production from the original treatment units, caused in part by a shifting allocation of treatment

347 effort away from original units to new ones, underlie the disproportionate response of adult sea

348 lamprey abundance to habitat increases. As expected, the average contribution of basin-wide sea

349 lamprey production from new treatment units increased in response to increasing absolute

350 amounts of new accessible habitat (Fig. 5a). Increasing habitat availability also caused a steep,

351 concurrent increase in production within the original treatment units (Fig. 5b); the nature of the

352 response was consistent across both types of habitat addition. This response may be explained in

353 part by the reduced overall annual treatment frequency among original treatment units with

354 increasing habitat additions (Fig. 5c). The average annual allocation of the control budget to

355 original treatment units declined from \$2.42 million to a median of \$2.07 and \$1.79 million for

356 the single and multiple treatment unit additions, respectively, when 18 new habitat blocks were

357 added to the Lake Michigan basin (Fig. 6).

358 Case Study 
All management scenarios pertaining to the Sixth Street Dam removal forecasted large

360 increases in adult sea lamprey abundance in Lake Michigan, assuming the control budget

361 remains unchanged (Fig. 7). Among the simulations, the lowest mean percent increase in adult

362 abundance from status quo conditions was 52\%. This occurred when the Webber Dam was

363 modified to block sea lamprey, new habitat units were treated, and sea lamprey used 10\% of

364 available habitat. For the same scenario, just over $24 \%$ of simulations resulted in abundances

365 exceeding the status quo $90^{\text {th }}$ percentile. The largest mean percent increase of $269 \%$ occurred

366 when an unmodified Webber Dam allowed sea lamprey to infest the Looking Glass River, none

367 of the new habitat units were treated, and sea lamprey used $50 \%$ of potentially available habitat.

368 Approximately $87 \%$ of simulations for this scenario resulted in spawner abundances exceeding

369 the status quo $90^{\text {th }}$ percentile.

370 The decision to modify the Webber Dam, the decision to treat the upstream Grand River,

371 and the assumed degree of habitat use each had substantial effects on equilibrium sea lamprey

372 abundances, but the relative magnitude of effects differed. When the decision to treat and

373 assumed habitat use were otherwise held constant among scenarios, the percent difference in

374 mean lake-wide sea lamprey abundance between simulations including and excluding the

375 Looking Glass River ranged between $13.1 \%$ and $19.6 \%$, with higher simulated abundances for

376 scenarios including the Looking Glass River. The decision whether or not to treat the upstream

377 Grand River system had a larger effect on sea lamprey numbers than the decision to modify

378 Webber Dam, with the decision to not treat these units resulting in a $40.4 \%$ to $52.1 \%$ increase in

379 average adult abundance. Assuming greater habitat utilization in the new treatment units had a

380 similarly large effect on equilibrium sea lamprey abundances ( $34.7 \%$ to $49.1 \%$ increase). 
381 For the barrier removal scenario in which upstream habitat is treated and the Webber 382 Dam is modified to block sea lamprey, substantial increases in the annual Lake Michigan control 383 budget were needed to restore mean sea lamprey abundances to levels at or below status quo 384 under the two assumptions of habitat use. Simulations suggested an annual control budget of $385 \$ 2.62$ million per year, representing a \$200 000 increase from the current budget, was needed to 386 maintain mean abundances at or just below status quo levels when assumed habitat use was $10 \%$ 387 (Fig. 8). A control budget of $\$ 2.78$ million was required when assumed habitat use was $50 \%$, 388 representing an annual budget increase of $\$ 360000$. 


\section{Discussion}

The systematic habitat addition simulations showed that a heavily-controlled invasive species, like sea lamprey, responds to the localized easing of key management-imposed constraints in a disproportionate manner. The primary constraints on sea lamprey population growth in the Great Lakes are habitat limitations created by barriers in large river systems and lampricide treatment-induced mortality at the larval stage (Christie et al. 2003; Lavis et al. 2003).

When these two constraints were diminished by the addition of habitat and the subsequent shifting of treatment efforts to these new habitat blocks, simulated sea lamprey production increased in both the new and original river systems, leading to a large increase in forecasted adult abundance. Similarly strong responses in population abundance to changing top-down controls have been observed for mesopredators (i.e., mesopredator release), where small reductions in the abundance of apex predators trigger disproportionate increases in mesopredator abundance (Ritchie and Johnson 2009). There is also evidence for sea lamprey of large population responses to barrier failures in Lake Michigan: unrestricted colonization of $220 \mathrm{~km}$ of the Manistique River above a degraded barrier in the late 1990s and early 2000s was associated with approximately a $100 \%$ increase in the estimated Lake Michigan sea lamprey abundance (Klar and Young 2004).

The forecasted disproportionate response can be explained in part by production of sea lamprey from newly available habitat and in part by dilution of control intensity across the basin.

First, the simulated population increased due to an immediate contribution of sea lamprey production from new habitats. Second, shifts in control effort allocation to include new treatment units led to an overall simulated decrease in treatment frequency for the original treatment units, which led to increased production, on average, from the these units. 
We further hypothesize that the lack of density-dependent controls on this already

413 suppressed population compounded these shifts in treatment allocation and total sea lamprey

414 producing habitat by giving rise to a positive feedback effect. The sea lamprey population in

415 Lake Michigan has been reduced to abundances far below carrying capacity, defined at the lake-

416 level by limits on the abundance of available hosts; contemporary abundances are believed to be

417 at or below $10 \%$ of pre-control levels, and host abundances are much higher than they were at

418 the start of the control program. Consequently, the modeled population is not regulated by

419 density-dependent processes when management actions allow for increased recruitment except in

420 rare instances when large recruitment events trigger density-dependent compensation at the

421 individual stream level. In the near absence of density-dependent regulation, a positive feedback

422 cycle allows the population to rise to a carrying capacity defined by the estimated stream-level

423 stock-recruitment dynamics (Dawson and Jones 2009), subject to constraints imposed by a

424 density-independent lampricide control program. It is possible that the size to which the lamprey

425 population grows would be lower than forecasted in the more extreme scenarios modeled here,

426 constrained by host dynamics. The abundances would, nevertheless, be large enough to inflict

427 severe damage on host populations. Positive feedback effects have been predicted for other

428 fisheries systems under changing predation pressure (Kirby et al. 2009; Audzijonyte et al. 2013).

429 In total, the simulated new production from new habitats, increased production from old

430 habitats due to shifted control efforts, and the near absence of density-dependent compensation at

431 current sea lamprey abundance levels drove the large forecasted response in sea lamprey

432 abundance from a comparatively small increase in habitat. These results suggest that future

433 evaluations of barrier removals focusing on potential fish responses should consider broader

434 spatial scales, especially for systems in which species do not exhibit strict natal homing and 
435 control effort is necessarily balanced among many streams. Without considering lake-wide

436 impacts of small-scale barrier removals, we would not have forecasted the disproportionate 437 population response.

438 Similar types of population responses to increased accessible spawning and rearing 439 habitat may occur for desirable fish species in the Great Lakes. Although many species relying 440 on nearshore or riverine habitat for spawning are known to exhibit homing behavior, increased 441 reproduction coupled with modest rates of straying from natal habitats could enhance future 442 reproductive success across broader spatial scales. Lake sturgeon and lake trout (Salvelinus 443 namaycush) were observed to exhibit overall straying rates of 0.105 and 0.60 in Lake Michigan, 444 while walleye (Sander vitreus) in Lake Erie exhibit moderate gene flow among populations 445 (Bronte et al. 2007; Strange and Stepien 2007; Homola et al. 2012). Although not assessed in the 446 Great Lakes, the straying rates of Chinook salmon (Oncorhyncus tshawytscha) ranged from 0.01 447 to 1.0 among spawning tributaries in Washington's Wenatchee River (Ford et al. 2015). Our analysis also revealed that barrier removal decisions need to account for factors in 449 addition to habitat quantity to accurately assess the effects of barrier removal. The difference 450 between opening a single large river and multiple small river systems is due to the challenge of 451 incorporating increasingly expensive single-system treatments into the stream ranking system; if 452 there is insufficient budget remaining when a unit ranks for treatment, it will be passed over in 453 favor of lower ranked, less expensive systems. Supporting this, simulated trends in budget 454 expenditure and treatment frequency among original treatment units flatten with increasing 455 habitat availability only for the single large river addition (Figs. 5c, 6), while lamprey production 456 from this new habitat increases more steeply (Fig. 5a). Habitat attributes of recruitment potential 457 and spawner allocation, the latter associated with geographic location, also played important 
458 roles in mediating the sea lamprey response to increasing barrier removals. Expected differences

459 among these habitat attribute scenarios may be mitigated by more flexible management strategies

460 (e.g., based in part on professional judgment rather than a fixed algorithm) capable of accounting

461 for higher sea lamprey output from larger, more productive systems.

462 The high degree of variability within each of the barrier removal scenarios reflects very

463 real uncertainty in our understanding of sea lamprey dynamics and should be explicitly

464 recognized in decision making. One of the strengths of the MSE approach is the incorporation of

465 multiple sources of uncertainty (Bunnefeld et al. 2011); for our model, these sources included

466 stochasticity in biological processes, larval abundance assessments, and control efforts. The

467 resulting variability in model results implies that the forecasted mean responses in abundance are

468 by no means guaranteed outcomes. Instead, the results indicate a wide range of plausible

469 alternative outcomes. Reporting results as proportions of simulations with values above some

470 management-relevant threshold value demonstrates the likelihood of an undesirable outcome,

471 rather than simply focusing on a "best-guess"; decision-makers can use this information to assess

472 the risk of key decisions.

473 Simulation results for the removal of the Sixth Street Dam confirmed trends forecasted in

474 simulations of systematically increasing habitat availability. The case study also highlights the

475 importance of treating the upstream Grand River in the case of barrier removal. To ignore the

476 newly infested upstream habitat and continue a status quo treatment program resulted in

477 markedly higher sea lamprey abundances, despite the dilution of basin-wide treatment effort that

478 would have occurred if upstream habitat had been treated. The estimated increases in control

479 budget necessary to maintain sea lamprey at status quo abundances provide decision makers with

480 an estimate of the cost of a barrier removal. There are numerous other potential barrier removals 
481 under consideration in the Great Lakes, including those in Lake Michigan's Boardman River and

482 Lake Superior's Black Sturgeon River, that could be evaluated with this MSE tool.

The case study simulations depended on several assumptions: that the Sixth Street Dam

484 will not be replaced by a seasonal barrier, that migrating sea lamprey will eventually utilize all

485 identified upstream tributary systems, and that the evaluated percent habitat use values $(10 \%$,

$48650 \%$ ) bracket realistic values. Stakeholder groups have proposed the construction of a

487 seasonally-adjusted structure, in place of the Sixth Street Dam, to operate as a barrier only during

488 sea lamprey migrations (Adair and Sullivan 2015). We chose not to account for this possibility

489 in simulating the removal due to the uncertainty surrounding its actual installation and potential

490 success at blocking sea lamprey. If the goals of such a barrier are blocking sea lamprey and

491 allowing passage of other non-jumping, migratory species, the overlapping migration

492 phenologies of Great Lakes fish largely prevent the balancing of such objectives without

493 installation of an effective fishway (Vélez-Espino et al. 2011). Even partial barrier failures can

494 contribute to large increases in lake-wide sea lamprey abundances, as demonstrated by the

495 historical failure of a barrier on Michigan's Manistique River (Klar and Young 2004). The

496 assumption that sea lamprey can and will use all identified upstream tributaries for spawning has

497 been largely supported by previous barrier removal studies and our understanding of sea lamprey

498 migratory capacity. In coastal river systems smaller than the Grand River, sea lamprey have

499 been observed to quickly re-colonize previously blocked upstream habitat (Hogg et al. 2013;

500 Lasne et al. 2014). Sea lamprey also appeared to rapidly colonize upstream reaches of the

501 Manistique River in northern Michigan, a river section over $220 \mathrm{~km}$ in length, following the

502 partial failure of a blocking barrier, and access upstream tributary systems in Portugal's River

503 Mondego, a river system draining a watershed slightly less than half the size of Michigan's 
504 Grand River (Almeida et al. 2002; Klar and Young 2004). Finally, we assumed sea lamprey

505 would likely use $10 \%$ of available river length in the upstream tributaries, and evaluated $50 \%$

506 habitat use as a worst-case scenario. Although the $10 \%$ assumption can be considered a

507 reasonable estimate based on professional judgment and preliminary analyses, it remains a rough

508 approximation. Identifying reliable habitat area estimates in future modeling endeavors will

509 require more detailed GIS data integrating length and width information along streams, as well

510 as an improved empirical understanding of habitat use by sea lamprey within tributaries.

511 Other modeling-based approaches have been used to inform barrier removal decisions

512 and predict fish response to changing habitat availability, but none have matched both the extent

513 and resolution of our modeling efforts for sea lamprey populations. At the broadest extent,

514 barrier removal prioritization efforts synthesize multiple sources of information and strive to

515 optimize barrier removals across varying spatial extents like the Great Lakes or Pacific

516 Northwest, but often make simplifying assumptions in relating passability, stream length, and

517 habitat quality to future fish production (Zheng et al. 2009; Kemp and O'Hanley 2010; Moody et

518 al. 2017). At a smaller spatial extent, landscape models are increasingly used to predict indirect

519 aspects of fish response to barrier removal, like spawning success; these models often fail to

520 provide direct estimates of fish abundance (Steel et al. 2004; Spens et al. 2007). Finer resolution

521 modeling has also occurred to predict scenario-specific fish responses to individual barrier

522 removals using species-specific, population dynamics models for American shad (Alosa

523 sapidissima), walleye, and American eels (Anguilla rostrata); (McCleave 2001; Cheng et al.

524 2006; Harris and Hightower 2012).

525 To our knowledge, no previous studies have assessed fish responses to barrier removal

526 using a detailed, species-specific management strategy evaluation approach across a spatial 
527 extent comparable to Lake Michigan, nor have they explicitly considered the implications of

528 barrier removals in a coupled management system with trade-offs. With sufficient demographic

529 information, this approach could be applied to other species of migratory fishes where

530 management is implemented at local scales but could potentially affect larger metapopulations.

531 Protection of ecosystems from invasive species and restoration of ecological connectivity in lotic

532 systems are two of the most important issues facing fishery managers in the Great Lakes and

533 elsewhere. Although focused on the former, the approach detailed in this report illustrates a tool

534 of potential utility for the challenge of reconciling these two issues. 


\section{Acknowledgments}

536 The authors would like to acknowledge Norine Dobiesz for contributions on model diagnostics

537 and modifications. Special thanks to Travis Brenden and Michael Wagner for reviewing and

538 commenting on an earlier version of the manuscript. The authors would also like to

539 acknowledge Aaron Jubar and Jenna Tews for providing key input data informing the case study

540 simulations. Finally, this work was made possible by funding from the Great Lakes Fishery

541 Commission. This is contribution \# 20xx-xx from the Quantitative Fisheries Center. 
542

543

544

545

546

547

548

549

550

551

552

553

554

555

556

557

558

559

560

561

562

563

\section{References}

Adair, R., and Sullivan, P. 2015. Sea lamprey control in the Great Lakes 2014. Annual Report to the Great Lakes Fishery Commission.

Almeida, P.R., Quintella, B.R., and Dias, N.M. 2002. Movement of radio-tagged anadromous sea lamprey during the spawning migration in the River Mondego (Portugal). Hydrobiologia 483(1): 1-8. doi:10.1023/A:1021383417816.

Applegate, V. C. 1950. Natural history of the sea lamprey, Petromyzon marinus in Michigan. U.S. Fish and Wildlife Service Special Scientific Report 55:1-60.

Audzijonyte, A., Kuparinen, A., Gorton, R., and Fulton, E.A. 2013. Ecological consequences of body size decline in harvested fish species: positive feedback loops in trophic interactions amplify human impact. Biology Letters 9(2): 20121103. doi:10.1098/rsbl.2012.1103.

Bednarek, A.T. 2001. Undamming rivers: a review of the ecological impacts of dam removal. Environmental Management 27(6): 803-814. doi: 10.1007/s002670010189.

Bergstedt, R.A., and Seelye, J.G. 1995. Evidence for lack of homing by sea lampreys. Transactions of the American Fisheries Society 124(2): 235-239. doi:10.1577/15488659(1995)124<0235:EFLOHB >2.3.CO;2.

Bondelid, T., Johnston, C., McKay, C., Moore, R., and Rea, A. 2010. NHDPlus Version 1 (NHDPlusV1) User Guide [online]. Available from ftp://ftp.horizonsystems.com/ nhdplus/nhdplusv1/documentation/nhdplusv1_userguide.pdf [accessed 1 May 2016]

Bronte, C.R., Holey, M.E., Madenjian, C.P., McKee, P.C., Toneys, M.L., Ebener, M.P., Breidert, B., Fleischer, G.W., Hess, R., Martell Jr., A.W., and Olsen, E.J. 2007. Relative abundance, site fidelity, and survival of adult lake trout in Lake Michigan from 1999 to 
564

565

566

567

568

569

570

571

572

573

574

575

576

577

578

579

580

581

582

2001: Implications for future restoration strategies. North American Journal of Fisheries Management 27(1): 137-155. doi: 10.1577/M05-214.2.

Bunnefeld, N., Hoshino, E., and Milner-Gulland, E.J. 2011. Management strategy evaluation: a powerful tool for conservation. Trends in Ecology and Evolution 26(9): 441-447. doi:10.1016/j.tree.2011.05.003.

Burroughs, B.A., Hayes, D.B., Klomp, K.D., Hansen, J.F., and Mistak, J. 2010. The effects of the Stronach Dam removal on fish in the Pine River, Manistee County, Michigan. Transactions of the American Fisheries Society 139(5): 1595-1613. doi:10.1577/T09056.1 .

Cheng, F., Zika, U., Banachowski, K., Gillenwater, D., and Granata, T. 2006. Modelling the effects of dam removal on migratory walleye (Sander vitreus) early life-history stages. River Research and Applications 22(8): 837-851. doi:10.1002/rra.939.

Christie, G., Adams, J.V., Steeves, T.B., Slade, J.W., Cuddy, D.W., Fodale, M.F., Young, R.J., Kuc, M., and Jones, M.L. 2003. Selecting Great Lakes streams for lampricide treatment based on larval sea lamprey surveys. Journal of Great Lakes Research 29: 152-160. doi:10.1016/S0380-1330(03)70484-5.

Dawson, H.A., and Jones, M.L. 2009. Factors affecting recruitment dynamics of Great Lakes sea lamprey (Petromyzon marinus) populations. Journal of Great Lakes Research 35(3): 353-360. doi:10.1016/j.jglr.2009.03.003.

Dawson, H.A., Jones, M.L., Irwin, B.J., Johnson, N.S., Wagner, M.C., and Szymanski, M.D. 2016. Management strategy evaluation of pheromone-baited trapping techniques to improve management of invasive sea lamprey. Natural Resource Modeling 29(3): 448469. doi:10.1111/nrm.12096. 
587

588

589

590

591

592

593

594

595

596

597

598

599

600

601

602

603

604

605

606

607

608

609

Doyle, M.W., Harbor, J.M., and Stanley, E.H. 2003. Towards policies and decision-making for dam removal. Environmental Management 31(4): 453-465. doi: 10.1007/s00267-0022819-z.

Ford, M.J., Murdoch, A., and Hughes, M. 2015. Using parentage analysis to estimate rates of straying and homing in Chinook salmon (Oncorhynchus tshawytscha). Molecular Ecology 24(5): 1109-1121. doi: 10.1111/mec.13091.

Great Lakes Fishery Commission. 2016. Sea Lamprey Control Map [online]. Available from http://data.glfc.org/ [accessed 30 August 2016]

Harris, J.E., and Hightower, J.E. 2012. Demographic population model for American shad: will access to additional habitat upstream of dams increase population sizes? Marine and Coastal Fisheries: Dynamics, Management, and Ecosystem Science 4(1): 262-283. doi:10.1080/19425120.2012.675969.

Harwood, J., and Stokes, K. 2003. Coping with uncertainty in ecological advice: lessons from fisheries. TRENDS in Ecology and Evolution 18(12): 617-622. doi:10.1016/j.tree.2003.08.001.

Hogg, R., Coghlan, S.M., Jr., and Zydlewski, J. 2013. Anadromous sea lampreys recolonize a Maine coastal river tributary after dam removal. Transactions of the American Fisheries Society 142(5): 1381-1394. doi:10.1080/00028487.2013.811103.

Homola, J.J., Scribner, K.T., Elliot, R.F., Donofrio, M.C., Kanefsky, J., Smith, K.M., and McNair, J.N. 2012. Genetically derived estimates of contemporary natural straying rates and historical gene flow among Lake Michigan lake sturgeon populations. Transactions of the American Fisheries Society 141(5): 1374-1388. doi: 10.1080/00028487.2012.694829. 
610 Hunn, J.B., and Youngs, W.D. 1980. Role of physical barriers in the control of sea lamprey

611 (Petromyzon marinus). Canadian Journal of Fisheries and Aquatic Sciences 37(11):

2118- 2122. doi:10.1139/f80-253.

613 Irwin, B.J., Liu, W., Bence, J.R., and Jones, M.L. 2012. Defining economic injury levels for sea

614 lamprey control in the Great Lakes basin. North American Journal of Fisheries

615 Management 32(4): 760-771. doi:10.1080/02755947.2012.685140.

616 Johnson, S.E., and Graber, B.E. 2002. Enlisting the social sciences in decisions about dam

617 removal. BioScience 52(8): 731-738. doi: 10.1641/0006-

$618 \quad 3568(2002) 052[0731:$ etssid]2.0.co;2

619 Jones, M.L., Bergstedt, R.A., Twohey, M.B., Fodale, M.F., Cuddy, D.W., and Slade, J.W.

620 2003. Compensatory mechanisms in Great Lakes sea lamprey populations: implications

621 for alternative controls. Journal of Great Lakes Research 29: 113-29. doi:10.1016/S0380-

$622 \quad 1330(03) 70481-\mathrm{X}$.

623 Jones, M.L., Irwin, B.J., Hansen, G.J.A., Dawson, H.A., Treble, A.J., Liu, W., Dai, W., and

624 Bence, J.R. 2009. An operating model for the integrated pest management of Great Lakes

625 sea lampreys. The Open Fish Science Journal 2: 59-73.

626 doi:10.2174/1874401X00902010059.

627 Kemp, P.S., and O'Hanley, J.R. 2010. Procedures for evaluating and prioritising the removal of

628 fish passage barriers: a synthesis. Fisheries Management and Ecology 17(4): 297-322.

$629 \quad$ doi:10.1111/j.1365-2400.2010.00751.x.

630 Kirby, R.R., Beaugrand, G., and Lindley, J.A. 2009. Synergistic effects of climate and fishing in 631 a marine ecosystem. Ecosystems 12(4): 548-561. doi:10.1007/s10021-009-9241-9. 
632 Klar, G.T., and Young, R.J. 2004. Integrated management of sea lampreys in the Great Lakes

633

634

635

636

637

638

639

640

641

642

643

644

645

646

647

648

649

650

651

652

653 2004. Annual Report to the Great Lakes Fishery Commission.

Lasne, E., Sabatié, M.-R., Jeannot, N., and Cucherousset, J. 2014. The effects of dam removal on river colonization by sea lamprey Petromyzon marinus. River Research and Applications 31(7): 904-911. doi:10.1002/rra.2789

Lavis, D.S., Hallett, A., Koon, E.M., and McAuley, T.C. 2003. History of and advances in barriers as an alternative method to suppress sea lampreys in the Great Lakes. Journal of Great Lakes Research 29: 362-372. doi:10.1016/S0380-1330(03)70500-0.

Limburg, K.E., and Waldman, J.R. 2009. Dramatic declines in North Atlantic diadromous fishes. BioScience 59(11): 955-965. doi:10.1525/bio.2009.59.11.7.

McCleave, J.D. 2001. Simulation of the impact of dams and fishing weirs on reproductive potential of silver-phase American eels in the Kennebec River basin, Maine. North American Journal of Fisheries Management 21(3): 592-605. doi:10.1577/15488675(2001)021<0592:SOTIOD>2.0.CO;2.

McLaughlin, R.L., Smyth, E.R.B., Castro-Santos, T., Jones, M.L., Koops, M.A., Pratt, T.C., and Vélez-Espino, L. 2013. Unintended consequences and trade-offs of fish passage. Fish and Fisheries 14(4): 580-604. doi: 10.1111/faf.12003.

Moody, A.T., Neeson, T.M., Wangen, S., Dischler, J., Diebel, M.W., Milt, A., Herbert, M., Khoury, M., Yacobson, E., Doran, P.J., Ferris, M.C., O’Hanley, J.R., and McIntyre, P. 2017. Pet project or best project? Online decision support tools for prioritizing barrier removals in the Great Lakes and beyond. Fisheries 42(1): 57-65. doi:10.1080/03632415.2016.1263195. 
654 Morman, R.H., Cuddy, D.W., and Rugen, P.C. 1980. Factors influencing the distribution of sea lamprey (Petromyzon marinus) in the Great Lakes. Canadian Journal of Fisheries and Aquatic Sciences 37(11): 1811-1826. doi:10.1139/f80-224.

Mullett, K.M., Heinrich, J.W., Adams, J.V., Young, R.J., Henson, M.P., McDonald, R.B., and Fodale, M.F. 2003. Estimating lake-wide abundance of spawning-phase sea lampreys (Petromyzon marinus) in the Great Lakes: extrapolating from sampled streams using regression models. Journal of Great Lakes Research 29: 240-252. doi:10.1016/S03801330(03)70492-4.

Rahel, F.J. 2013. Intentional fragmentation as a management strategy in aquatic systems. BioScience 63(5): 362-372. doi:10.1525/bio.2013.63.5.9.

Ritchie, E.G., and Johnson, C.N. 2009. Predator interactions, mesopredator release and biodiversity conservation. Ecology Letters 12(9): 982-998. doi:10.1111/j.14610248.2009.01347.x.

Sharov, A.A., and Liebhold, A.M. 1998. Bioeconomics of managing the spread of exotic species with barrier zones. Ecological Applications 8(3): 833-845. doi:10.2307/2641270. Quinlan, H.R., Weise, J.G., Weisser, J.W., and Young, R.J. 2003. Techniques and methods for estimating abundance of larval and metamorphosed sea lampreys in Great Lakes tributaries, 1995 to 2001. Journal of Great Lakes Research 29: 137-151. doi:100.1016/S0380-1330(03)70483-3. 
677 Smith, B.R., and Tibbles, J.J. 1980. Sea lamprey (Petromyzon marinus) in Lakes Huron,

678 Michigan, and Superior: history of invasion and control, 1936-78. Canadian Journal of

$679 \quad$ Fisheries and Aquatic Sciences 37(11): 1780-1801. doi:10.1139/f80-222.

680 Smith, A.D.M., Sainsbury, K.J., and Stevens, R.A. 1999. Implementing effective fisheriesmanagement systems - management strategy evaluation and the Australian partnership approach. ICES Journal of Marine Science 56(6): 967-979. doi:10.1006/jmsc.1999.0540.

Spens, J., Englund, G., and Lundqvist, H. 2007. Network connectivity and dispersal barriers: using geographical information system (GIS) tools to predict landscape scale distribution of a key predator (Esox lucius) among lakes. Journal of Applied Ecology 44(6): 1127-

Stanley, E.H., Catalano, M.J., Mercado-Silva, N., and Orr, C.H. 2007. Effects of dam removal on brook trout in a Wisconsin stream. River Research and Applications 23(7): 792-798. doi:10.1002/rra.1021.

Steel, E.A., Feist, B.E., Jensen, D.W., Pess, G.R., Sheer, M.B., Brauner, J.B., and Bilby, R.E. 2004. Landscape models to understand steelhead (Onchorhyncus mykiss) distribution and help prioritize barrier removals in the Willamette basin, Oregon, USA. Canadian Journal

694 Strange, R.M., and Stepien, C.A. 2007. Genetic divergence and connectivity among river and reef spawning groups of walleye (Sander vitreus) in Lake Erie. 64(3): 437-448. doi: 10.1139/F07-022.

van der Lee, A.S., and Koops, M.A. 2016. Are small fishes more sensitive to habitat loss? A generic size-based model. Canadian Journal of Fisheries and Aquatic Sciences 73(4): 716-726. doi:10.1139/cjfas-2015-0026. 
700 Vélez-Espino, L.A., McLaughlin, R.L., Jones, M.L., and Pratt, T.C. 2011. Demographic

701 analysis of trade-offs with deliberate fragmentation of streams: control of invasive

702 species versus protection of native species. Biological Conservation 144(3): 1068-1080.

$703 \quad$ doi:10.1016/j.biocon.2010.12.026.

704 Zheng, P.Q., Hobbs, B.F., and Koonce, J.F. 2009. Optimizing multiple dam removals under

705 multiple objectives: linking tributary habitat and the Lake Erie ecosystem. Water

706 Resources Research 45(12): W12417. doi:10.1029/2008WR007589. 


\section{Tables}

708 Table 1. Illustration of the simulated Grand River barrier removal scenarios (Fig. 7). The two

709 habitat use alternatives (i.e., 10\%, 50\%) were run for each of the four management scenarios

710 below, while simulations evaluating the effect of an increasing control budget were run only for

711 Scenario \#1.

\begin{tabular}{|c|c|c|c|}
\hline Scenario & $\begin{array}{l}\text { Treat habitat above } \\
\text { Sixth Street Dam? }\end{array}$ & $\begin{array}{c}\text { Allow infestation of } \\
\text { Looking Glass River? }\end{array}$ & Assumed habitat use \\
\hline 1 & Yes & No & $\begin{array}{l}10 \% \\
50 \%\end{array}$ \\
\hline 2 & No & No & $\begin{array}{l}10 \% \\
50 \%\end{array}$ \\
\hline 3 & Yes & Yes & $\begin{array}{l}10 \% \\
50 \%\end{array}$ \\
\hline 4 & No & Yes & $\begin{array}{l}10 \% \\
50 \%\end{array}$ \\
\hline
\end{tabular}

712 


\section{Figure Captions}

714 Figure 1. Conceptual diagram for the sea lamprey MSE model. Solid and dashed lines indicate 715 component linkages within and among the individual biological, observational, and management 716 models, respectively.

718 Figure 2. Map of the Grand River mainstem (a) and the modeled Grand River system between 719 the Sixth Street Dam and North Lansing Dam (b). Only those tributaries in (b) identified as 720 "New Grand River Treatment Units" were explicitly considered in the simulations, and the 721 numbers correspond to numbered treatment unit names in Table S1. River flowline data were 722 obtained from the National Hydrography Dataset Plus (Bondelid et al. 2010) and state boundary 723 lines were obtained from ESRI and TomTom North America, Inc.

725 Figure 3. Adult sea lamprey abundance trends with increasing habitat availability, assuming

726 habitat is added within a single treatment unit. High and low spawner allocation and recruitment

727 potential refer to the assignment of streams as northern or southern streams and regular or

728 irregular producers, respectively. Boxes, whisker bars, and open circles represent the 25th and

72975 th, 10th and 90th, and 5th and 95th percentiles of simulated adult abundances, respectively.

730 Solid horizontal lines and black circles represent corresponding median and mean values,

731 respectively, and the gray squares indicate proportions of simulations with abundances greater

732 than the status quo 90th percentile.

733

734 Figure 4. Adult sea lamprey abundance trends with increasing habitat availability, assuming

735 habitat is added as independent treatment units. Boxes, whisker bars, and open circles represent 
736 the 25 th and 75 th, 10th and 90th, and 5th and 95th percentiles of simulated adult abundances,

737 respectively. Solid horizontal lines and black circles represent corresponding median and mean

738 values, respectively, and the gray squares indicate proportions of simulations with abundances

739 greater than the status quo 90th percentile. The asterisk indicates mean lamprey abundance from

740 Scenario \#1 of the Grand River case study, with an assumed 10\% habitat use (see Figure 7).

742 Figure 5. Changing model characteristics with increasing habitat. Lines and polygons represent

743 the median and $10^{\text {th }}$ and $90^{\text {th }}$ percentiles, respectively, across all simulations $(\mathrm{a}, \mathrm{b})$ or treatment

744 units (c). The dashed line and lighter polygon illustrate the effect of adding a single, large unit,

745 and the solid line and darker polygon illustrate the addition of habitat as multiple, discrete

746 treatment units, respectively.

748 Figure 6. Average annual budget expenditure on the original treatment units with increasing

749 habitat availability. The dashed and solid lines illustrate the response when habitat is added as a

750 single, ever-larger system and multiple, discrete treatment units, respectively.

752 Figure 7. Expected sea lamprey abundances for each of the management scenarios. Scenarios

753 \#1 and \#2 exclude the Looking Glass River, while Scenarios \#3 and \#4 account for its influence.

754 New treatment units are treated by the SLCP in Scenarios \#1 and \#3, and ignored in Scenarios \#2

755 and \#4. Boxes, whisker bars, and open circles represent the $25^{\text {th }}$ and $75^{\text {th }}, 10^{\text {th }}$ and $90^{\text {th }}$, and $5^{\text {th }}$

756 and $95^{\text {th }}$ percentiles of simulated adult abundances, respectively. The solid horizontal lines and

757 black circles represent median and mean values, respectively. Numbers above the upper whisker

758 bars indicate the proportion of simulations greater than the status quo $90^{\text {th }}$ percentile. 
760 Figure 8. Expected sea lamprey abundances when the Sixth Street Dam is removed, the Webber

761 Dam is modified to block sea lamprey, lamprey are assumed to use $10 \%$ (a) or $50 \%$ (b) of

762 maximum potential river length, and the new treatment units are allocated control efforts with a

763 steadily increasing Lake Michigan control budget. Boxes, whisker bars, and open circles

764 represent the $25^{\text {th }}$ and $75^{\text {th }}, 10^{\text {th }}$ and $90^{\text {th }}$, and $5^{\text {th }}$ and $95^{\text {th }}$ percentiles of simulated adult

765 abundances, respectively. The solid horizontal lines and black circles represent median and

766 mean values, respectively. 


\section{Canadian Journal of Fisheries and Aquatic Sciences}

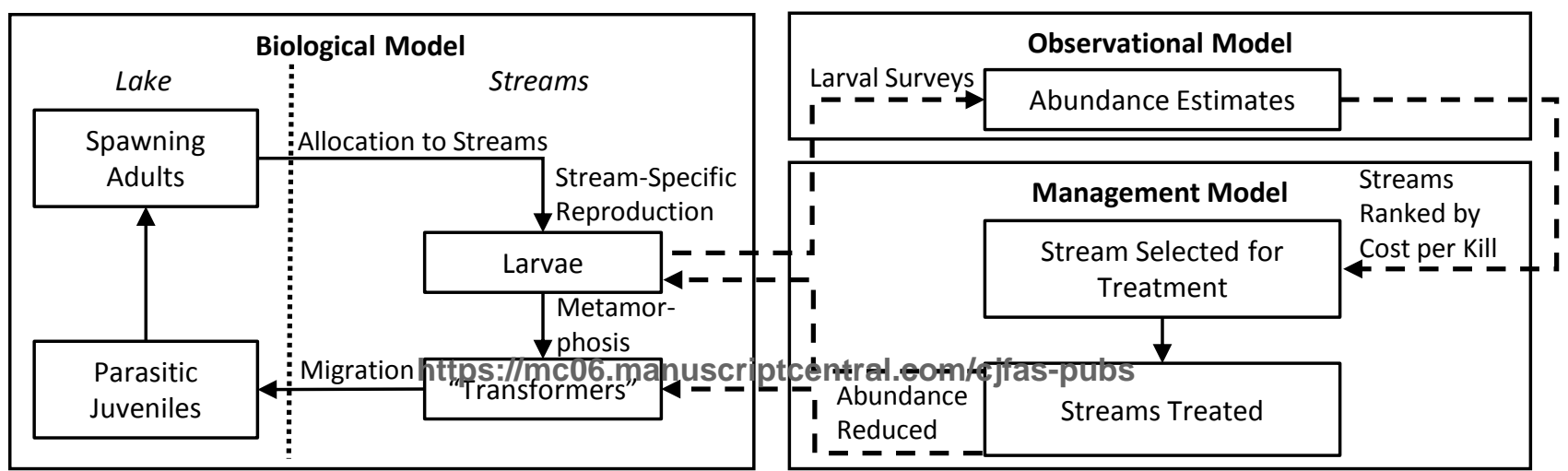




\section{Page 41 of 47 Canadian Journal of Fisheries and Aquatic Sciences}

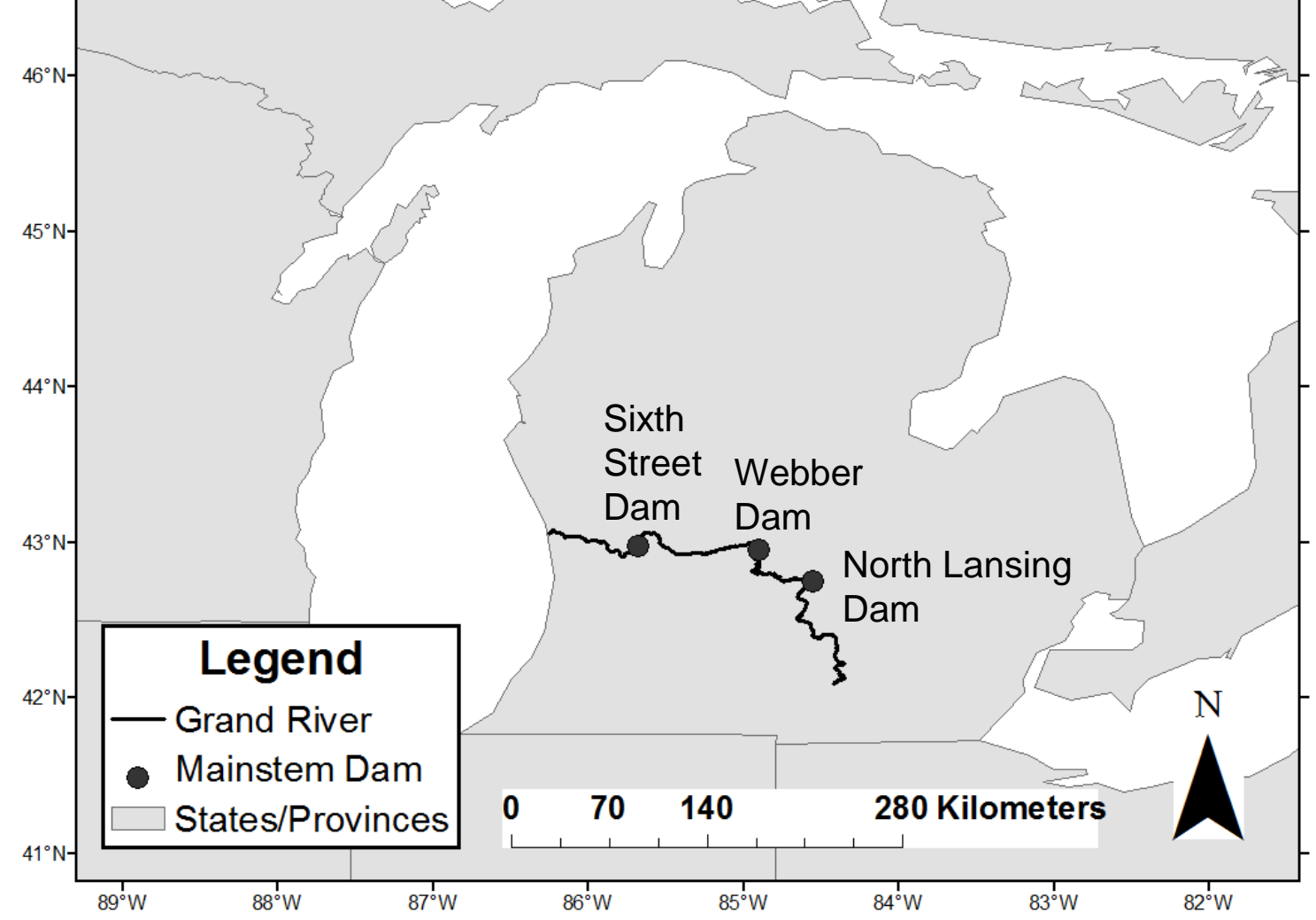

b)

Sixth Street Dam

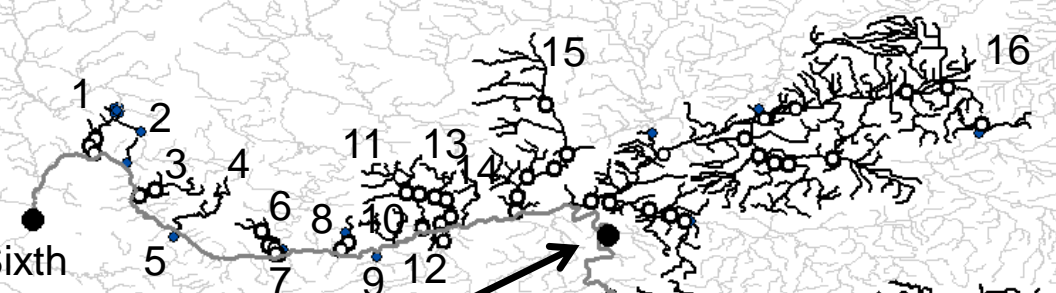
912 Webber Dam

\section{Legend}

Grand River Mainstem

New Grand River Treatment Units Non-Prioritized Stream Features

- Tributary Dam

- Mainstem Dam

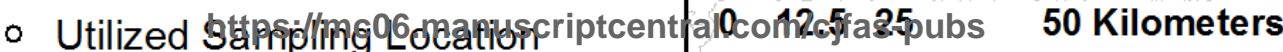

North Lansing Dam 
Canadian Journal of Fisheries and Aquatic Sciences Page 42 of 47

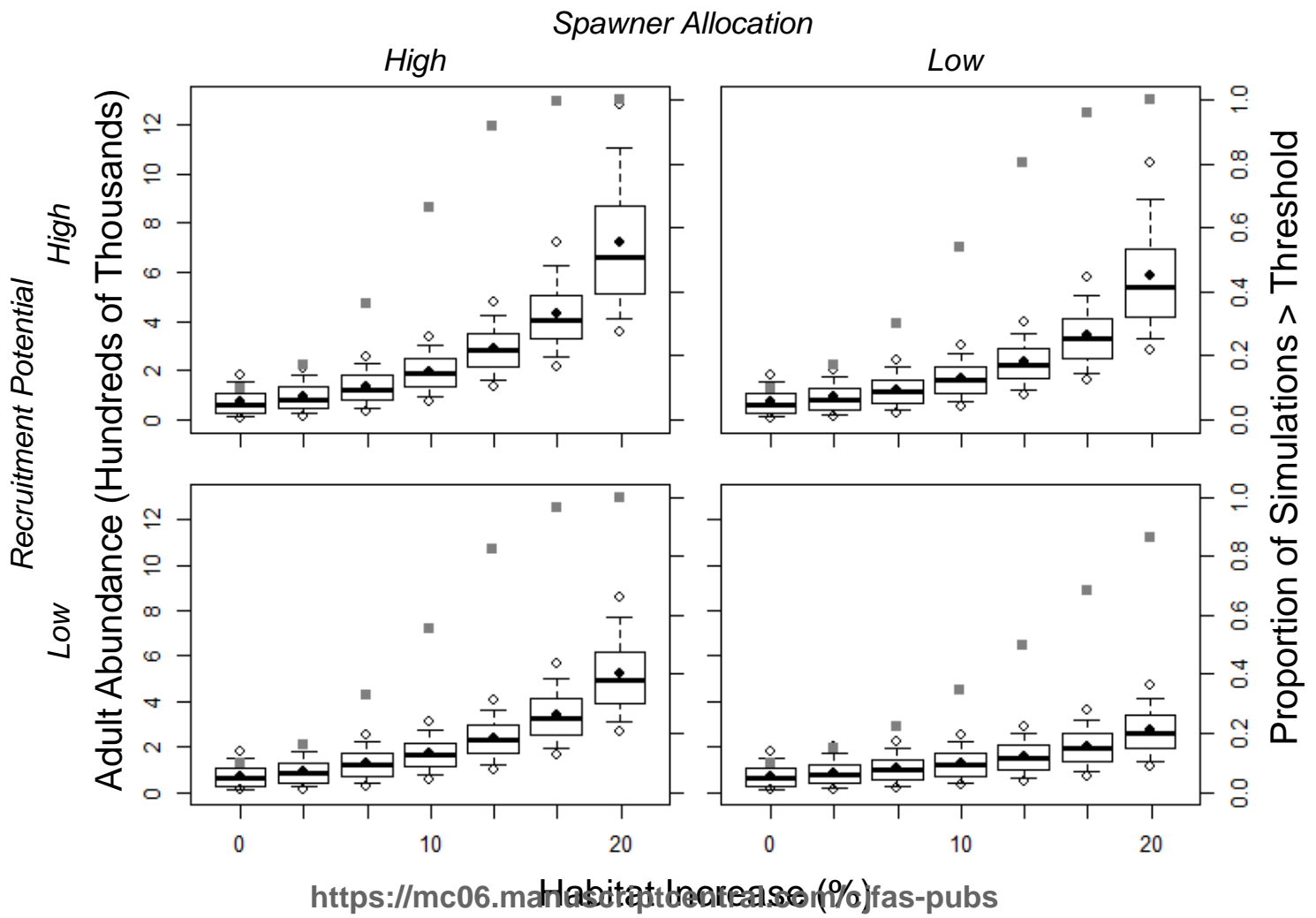




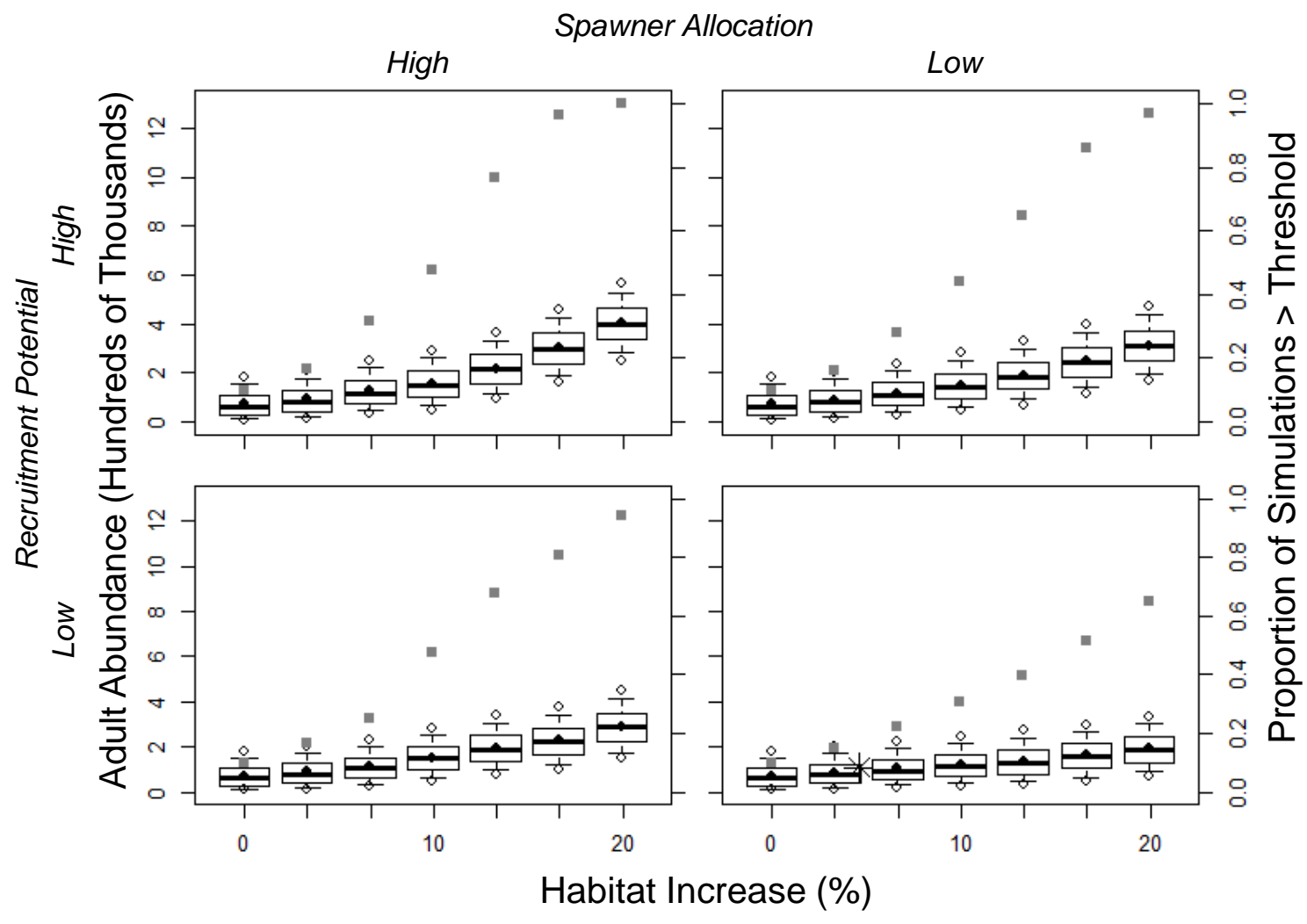



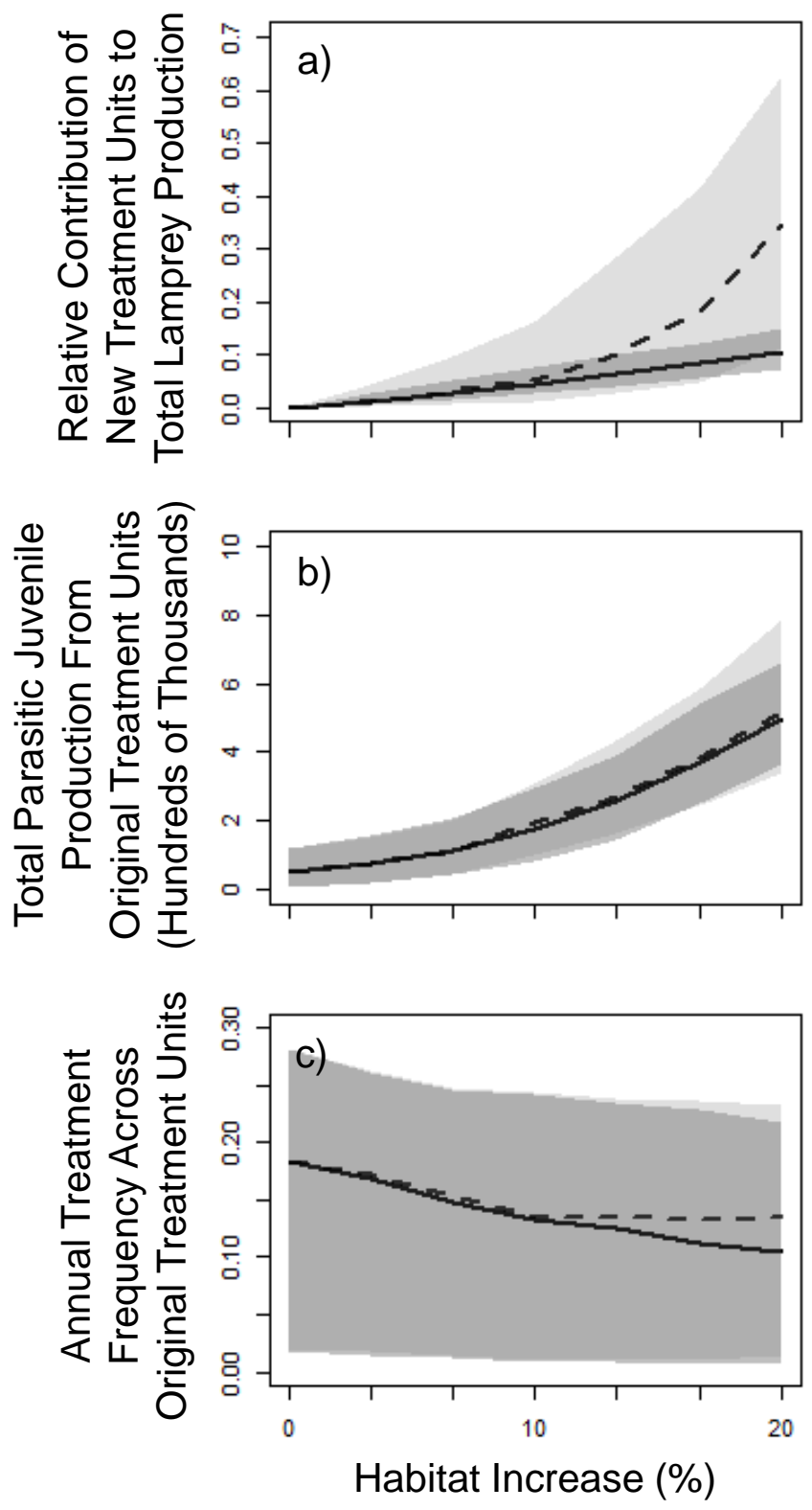


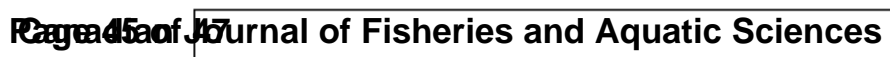

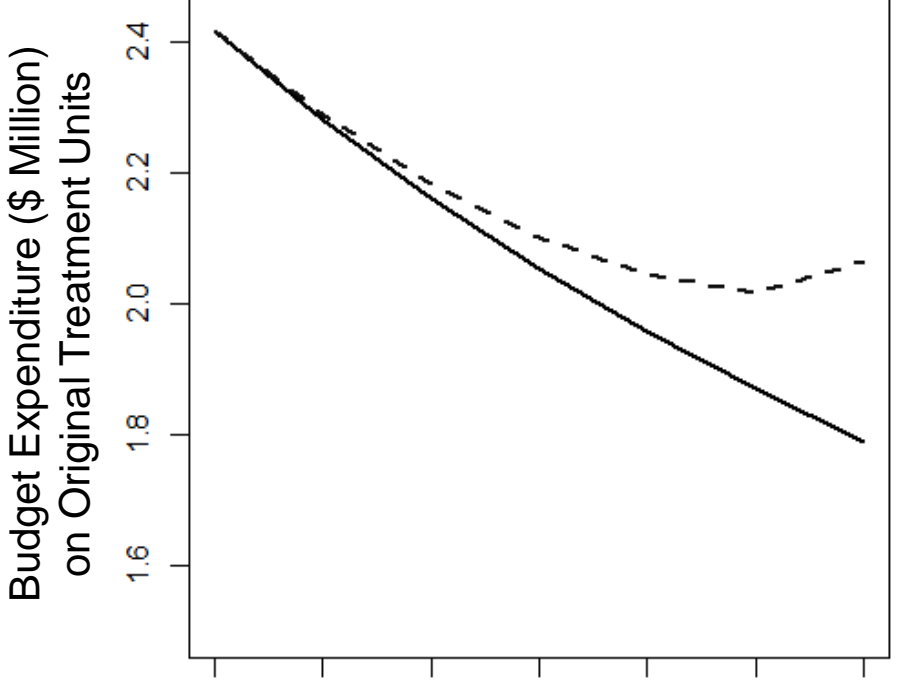

https://mc006.manuscriptcentral.com/cjfas-pubs ${ }^{20}$ Habitat Increase (\%) 
Canadian Journal of Fisheries and Aquatic Scieneage 46 of 47

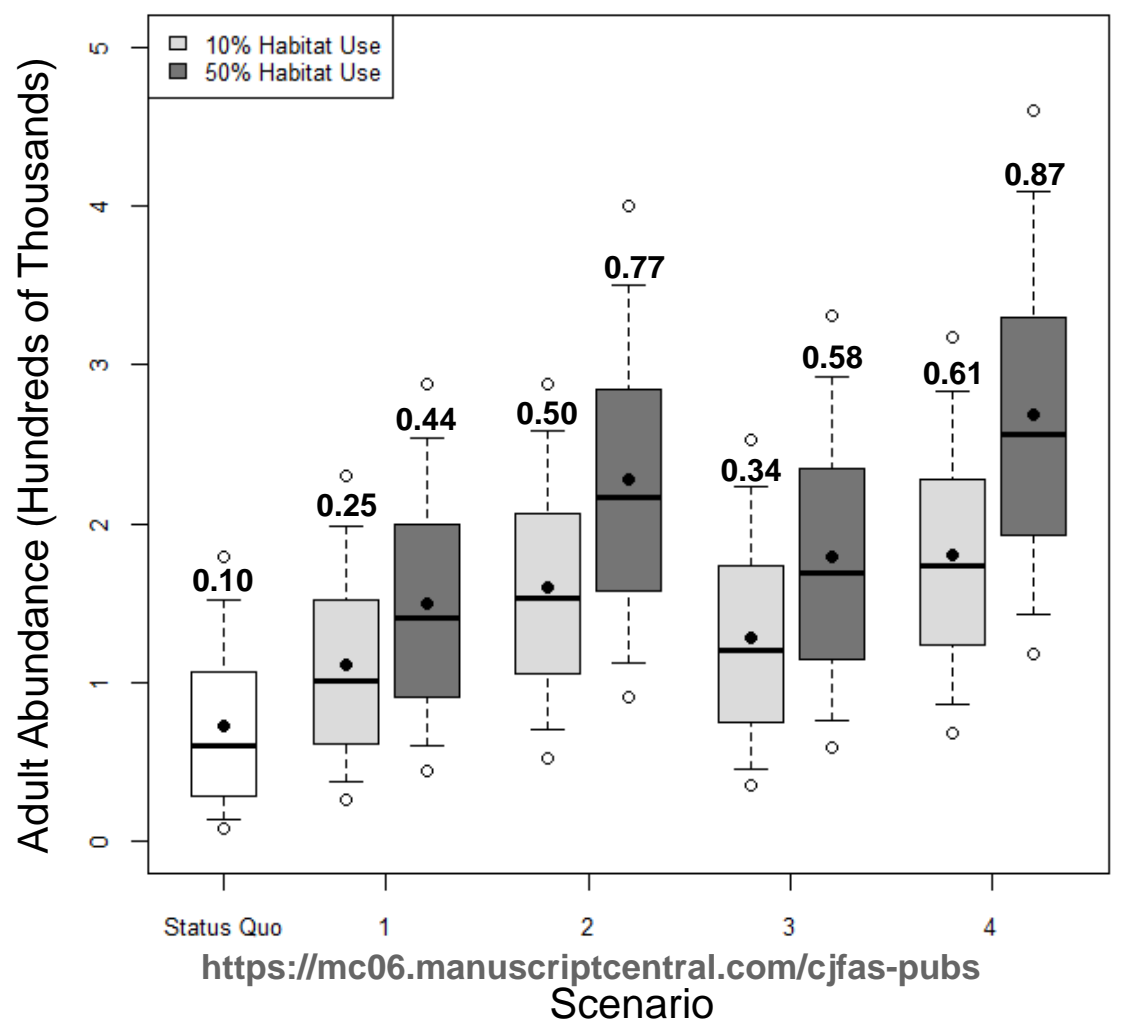


